\title{
A linguagem científica como uma modalidade da linguagem semiótica no contexto da formação interdisciplinar online de professores de Ciências
}

\author{
El lenguaje científico como una modalidad del lenguaje semiótico en el \\ contexto de la formación interdisciplinaria en línea de profesores de \\ Ciencias
}

\section{Scientific language as a modality of semiotic language in the context of online interdisciplinary formation of science teachers}

Franciele Ruas ${ }^{1}$

Valmir Heckler ${ }^{2}$

Rafaele Araújo ${ }^{3}$

\begin{abstract}
Resumo
Este trabalho visa a discussão a respeito da linguagem na formação online de professores de Ciências na perspectiva interdisciplinar da Universidade Federal do Rio Grande - FURG. Para isso, traçam-se os argumentos que caracterizam esse espaço de formação inicial do curso de Licenciatura em Ciências como uma comunidade, composta por sujeitos que se comunicam em uma linguagem intrínseca das Ciências. Diante disso, investiga-se como a linguagem é empregada para expressar significados e como influencia nas ações semióticas nesta comunidade de formação de professores. Como instrumento para a coleta de informações qualitativas, foi utilizado às linguagens construídas e registradas em uma das aulas registradas no Ambiente Virtual de Aprendizagem - AVA Moodle do curso. Nesse viés, prima-se inicialmente em discutir a linguagem como um campo de estudo da semiótica, na qual constitui as mais variadas formas de comunicação em um contexto social, utilizando-se de distintos signos que podem ser representados por imagens, palavras, gestos, gráficos, símbolos, dentre outros, manifestando-se de maneira verbal (oral ou escrita) e não-verbal. Entre os resultados do estudo registra-se que ao permitir que os estudantes construam seus próprios modelos explicativos, possibilita-se a interação tanto com a linguagem dos materiais de estudo disponíveis na sala de aula virtual (textos e vídeo) quanto pela linguagem entre os professores/tutores e estudantes, na expressão dos significados e na composição das ações e práticas semióticas nesta comunidade. Assume-se assim a linguagem científica como uma modalidade da linguagem semiótica, em que se recorre a ela para o entendimento de fenômenos da natureza.
\end{abstract}

Palavras-chave: Linguagem semiótica; linguagem científica; formação de professores online; interdisciplinaridade; Ciências da Natureza.

\section{Resumen}

Este trabajo busca la discusión acerca del lenguaje en la formación online de profesores de Ciencias en la perspectiva interdisciplinaria de la Universidad Federal de Rio Grande - FURG. Para ello, se trazan los argumentos que caracterizan ese espacio de formación inicial del curso de Licenciatura en Ciencias como una comunidad, compuesta por sujetos que se comunican en un lenguaje intrínseco de las Ciencias. Por lo tanto, se investiga como el lenguaje se emplea para expresar significados y cómo influye en las acciones semióticas en esta comunidad de formación de profesores. Como instrumento para la recolección de informaciones cualitativas, fue utilizado a los lenguajes construidos y registrados en una de las clases registradas en el Ambiente Virtual de Aprendizaje - AVA Moodle del curso. En este sentido, se prima inicialmente en discutir el lenguaje como un campo de estudio de la semiótica, en la que constituye las más variadas formas de

${ }^{1}$ Doutoranda no Programa de Pós-Graduação em Educação em Ciências da Universidade Federal do Rio Grande; RS; Brasil; f.p.ruas@gmail.com

${ }^{2}$ Doutor em Educação em Ciências pela Universidade Federal do Rio Grande; RS; Brasil; valmirheckler@gmail.com

${ }^{3}$ Doutora em Educação em Ciências pela Universidade Federal do Rio Grande; RS; Brasil; araujo.r.rafa@gmail.com 
comunicación en un contexto social, utilizando de distintos signos que pueden ser representados por imágenes, palabras, gestos, gráficos, símbolos, entre otros, manifestándose de manera verbal (oral o escrita) y no verbal. Entre los resultados del estudio se registra que al permitir que los estudiantes construyan sus propios modelos explicativos, se permite la interacción tanto con el lenguaje de los materiales de estudio disponibles en el aula virtual (textos y vídeo) como por el lenguaje entre los profesores / tutores y estudiantes, en la expresión de los significados y en la composición de las acciones y prácticas semioticas en esta comunidad. Se asume así el lenguaje científico como una modalidad del lenguaje semiótico, en que se recurre a ella para el entendimiento de fenómenos de la naturaleza.

Palabras claves: Lengua semiótica; lenguaje científico; formación de profesores en línea; interdisciplinariedad; Ciéncias de la naturaleza.

Abstract

This work aims at the discussion about the language in the online formation of science teachers in the interdisciplinary perspective of the Federal University of Rio Grande - FURG. For this, the arguments that characterize this space of initial formation of the Degree in Sciences as a community, composed of subjects that communicate in an intrinsic language of the Sciences are traced. Therefore, it is investigated how language is used to express meanings and how it influences the semiotic actions in this community of teacher training. As an instrument for the collection of qualitative information, it was used to the languages built and registered in one of the classes registered in the Virtual Learning Environment - AVA Moodle of the course. In this bias, we firstly discuss language as a field of study of semiotics, in which it constitutes the most varied forms of communication in a social context, using distinct signs that can be represented by images, words, gestures, graphs, symbols, among others, manifesting verbal (oral or written) and non-verbal. Among the results of the study is that by allowing students to construct their own explanatory models, it is possible to interact with both the language of the study materials available in the virtual classroom (texts and video) and the language among the teachers / tutors and students, in the expression of the meanings and in the composition of the actions and semiotic practices in this community. Thus scientific language is assumed as a modality of semiotic language, in which it is used to understand phenomena of nature.

Keywords: Semiotic language; scientific language; online teacher training; interdisciplinarity; Science of Nature.

\section{Introdução}

Iniciamos o processo de escrita deste artigo, recorte de uma pesquisa de doutorado, ascendendo a discussão a respeito da formação de professores de Ciências na perspectiva interdisciplinar, bem como traçando os argumentos que a caracterizam como uma comunidade, composta por licenciandos, professores formadores e professores tutores. Estes sujeitos imersos em seu contexto se comunicam em uma linguagem intrínseca das Ciências, que em tese, influencia na construção da aprendizagem mediante sua apropriação. Nesse viés, nos assumimos como parte desta comunidade, mediante a atuação da primeira autora na tutoria.

O lócus principal para a construção e registro das linguagens entre os indivíduos, foi constituído coletivamente no Ambiente Virtual de Aprendizagem - AVA Moodle da Universidade Federal do Rio Grande - FURG, tendo em vista à modalidade a distância do curso de Licenciatura em Ciências. A fim de delimitar as discussões tecidas neste artigo, estaremos voltados para uma das aulas propostas pelos professores formadores, nomeada por “Terceira e Quarta Parada". A mesma encontra-se presente na interdisciplina "Fenômenos da 
Natureza I" do primeiro semestre no percurso formativo do curso em questão. No tópico a seguir, estaremos empenhados com a descrição da aula supracitada, mas antes traremos um breve panorama sobre o curso.

\section{Um panorama geral sobre o curso de Licenciatura em Ciências e a descrição da aula}

Levando em consideração que no Brasil o número de licenciados em Ciências atuando nos anos finais do Ensino Fundamental é baixo (FURG, 2018), e que a região de abrangência e atuação da Universidade Federal do Rio Grande - FURG apresenta uma situação similar, a universidade, objetivando diminuir essa carência, preparou a oferta do curso de Licenciatura em Ciências na modalidade à distância. Tal oferta visa contribuir para a formação inicial de docentes, bem como possibilitar a formação continuada aos que possuem Licenciatura Curta, ou outra formação que não nesta área. Isso permite proporcionar mais segurança e competência no que se refere a esta forma de trabalho, contribuindo para a Educação Básica que carece dessas habilidades.

Uma das formas que o Ministério da Educação - MEC encontrou para incentivar o aumento da procura pelos cursos de licenciaturas foi com a criação de cursos na modalidade a distância através da Universidade Aberta do Brasil - UAB possibilitando assim alcançar as localidades mais distantes dos centros universitários (BRASIL, 2007). A FURG atende as demandas dos municípios que fazem parte do chamado Cordão Litorâneo Sul Rio-Grandense, porém apenas alguns desses municípios como: São Lourenço do Sul, Santo Antônio da Patrulha, Santa Vitória do Palmar e Novo Hamburgo, solicitaram a oferta do curso de Ciências.

O referido curso tem oferta de trinta vagas para cada polo e o trabalho é mediado pelo uso das tecnologias da informação e comunicação (TIC), onde a comunicação entre professores formadores, professores tutores e alunos ocorre via/no ambiente virtual de aprendizagem - AVA e em três encontros presenciais por semestre.

O grupo de professores formadores, que ministra as disciplinas constituintes das interdisciplinas, trabalha em coletivo, o que envolve diversos institutos da universidade. Além desses profissionais, o curso também conta com o apoio de professores tutores a distância que atuam acompanhando o desenvolvimento dos alunos em cada atividade proposta por intermédio de interfaces/ferramentas da web 2.0, bem como tutores presenciais que atuam nos polos, a fim de propiciar o suporte necessário aos alunos. 
Pautando-se no fato de que o curso é composto por interdisciplinas que o perpassam do início ao fim, criadas no intuito de possibilitar a interdisciplinaridade, permitindo aos docentes planejarem e propor os conteúdos e as atividades de forma articulada, nosso foco nesse artigo está voltado para debater/analisar uma das aulas pertencentes a uma das interdisciplinas. A escolha de Fenômenos da Natureza I justifica-se por ter dentre os seus objetivos o de elaborar e discutir a modelagem e os modelos físicos, químicos e biológicos, atrelando-os no viés interdisciplinar. Nessa perspectiva, a aula que traremos para a análise é nomeada "Terceira e Quarta Parada" com duração quinzenal contendo atividades assíncronas, conforme exposto na figura 1.

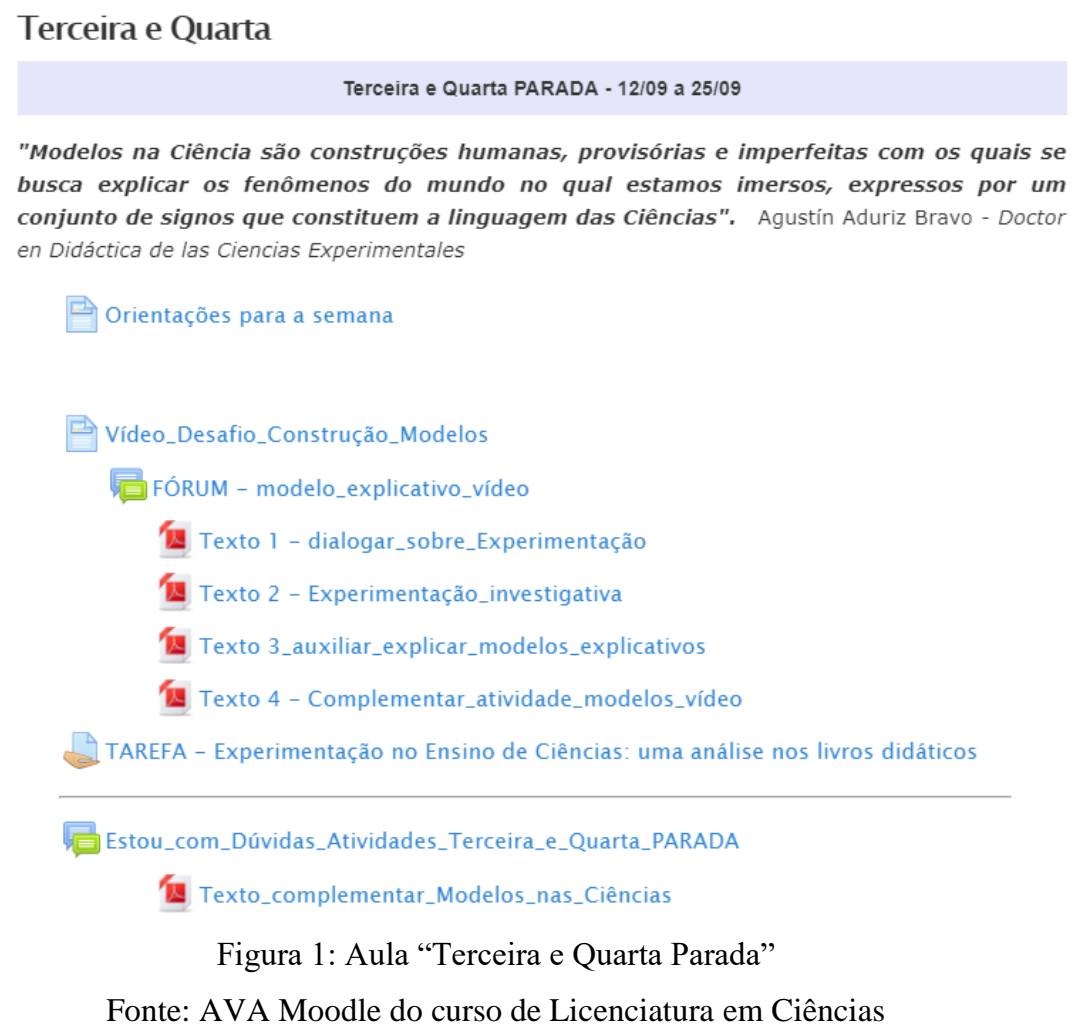

Na figura 1, registramos que nesta aula continham algumas tarefas, dentre as "Orientações para a semana" que os estudantes construíssem um modelo explicativo e refletissem sobre ele, enquanto metodologia, com a perspectiva de potencializar os processos de ensino e aprendizagem na sala de aula. Para tanto, os licenciandos deveriam assistir ao vídeo "Desafio da Construção de Modelos na Ciência" ${ }^{4}$ " sobre o experimento da caixa preta e o representar através de diagramas, desenhos, escrita, entre outras produções. A questão

\footnotetext{
${ }^{4}$ https://www.youtube.com/watch?v=a4Sr-0Tw7CQ e https://www.youtube.com/watch?v=a4Sr-0Tw7CQ
} 
central para nortear essa construção foi: "Que modelo explicativo você constrói para a situação visível e audível no vídeo?”.

O momento seguinte da atividade requeria que os estudantes realizassem a postagem dos modelos construídos no fórum "Modelo explicativo". Apesar de haver sessenta e seis estudantes ativos nessa interdisciplina, foram totalizados no fórum sessenta e uma postagens, com distintos modelos explicativos construídos pelos alunos dos quatro polos. Mantivemos em sigilo os nomes e imagens dos estudantes, tendo em vista que não lhes fora solicitada autorização para divulgação neste artigo.

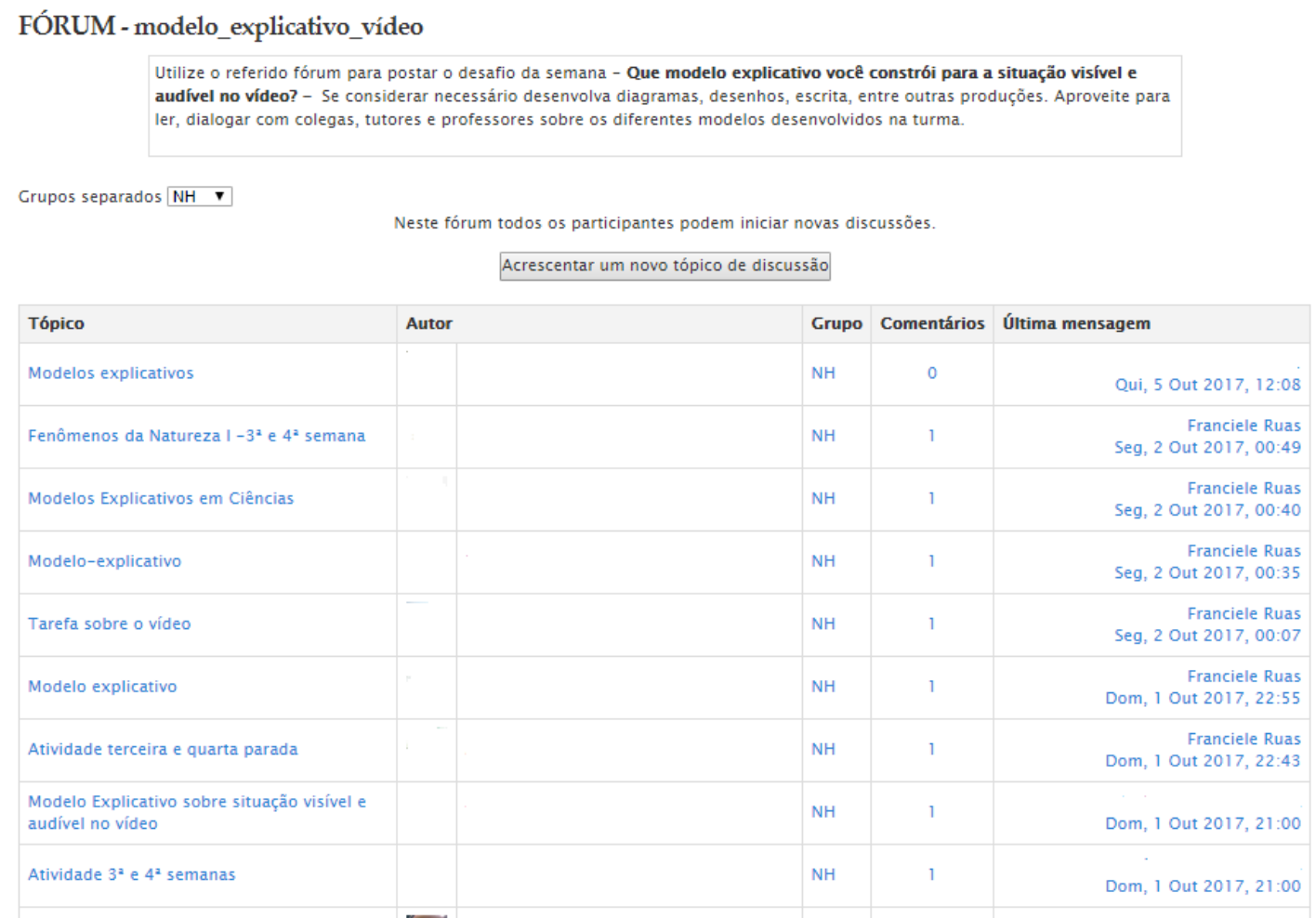

Figura 2: Postagem no fórum dos estudantes de um dos polos

Fonte: AVA Moodle do curso de Licenciatura em Ciências

A fim de complementar os diálogos com os colegas, tutores e professores sobre os diferentes modelos desenvolvidos na turma, bem como sobre a experimentação na sala de aula como metodologia para o ensino de Ciências, foram disponibilizados para leitura complementar quatro textos: "Vamos dialogar sobre o experimento desenvolvido, a partir do vídeo?", "Experimentação Investigativa: cooperar o fenômeno em imersão na linguagem"',

\footnotetext{
${ }^{5} \mathrm{http}: / /$ sabercom.furg.br/bitstream/1/1615/1/dialogar_sobre_experimento\%20.pdf

${ }^{6} \mathrm{http}: / /$ www.nutes.ufrj.br/abrapec/ixenpec/atas/resumos/R1187-1.pdf
} 
"Modelos Explicativos nas Ciências"” e "Texto 4 - Complementar para os desafios emergentes ao longo do desenvolver da atividade ${ }^{8}$.

Após a leitura dos textos, fora solicitado como fechamento da aula a tarefa "Experimentação no Ensino de Ciências: uma análise nos livros didáticos", na qual os estudantes deveriam pesquisar em livros didáticos de ciências $\left(6^{\circ}\right.$ ao $9^{\circ}$ ano) que outros modelos explicativos poderiam ser encontrados no artefato, a fim de se pensar as propostas metodológicas, modelos explicativos e a experimentação.

\section{A linguagem científica como modalidade da linguagem semiótica}

Com o propósito de ampliarmos a investigação sobre como a linguagem é empregada para expressar significados na compreensão dos fenômenos através da construção dos modelos explicativos e como influencia nas ações semióticas nesta comunidade de formação de professores, discutiremos a nível teórico a relação existente linguagem, semiótica e ciência.

A semiótica compreende os tipos de linguagem, ou seja, os modos de comunicação social que no interior de uma pluralidade de simbólicos constitui significados e são significantes socialmente. Nossas produções diárias como: escritas, livros, revistas, filmes, músicas, dentre outras, são permeadas de informações que a todo o momento desejam transmitir algum tipo de mensagem, estas podem ser definidas como práticas sociais que visam à busca de um sentido cultural. No que tange a compreensão de fenômenos dos mais variados tipos, a semiótica também está implicada ao visar sua ação como um signo (SANTAELLA, 2003).

O signo possui distintas naturezas e pode ser definido como um mediador que visa representar algum objeto, mas que não é o objeto em si, isto é, configura-se como um simbólico. A partir disso quem interpretará o signo utilizará outro signo para significar o primeiro, assim:

[...] o significado de um signo é outro signo- seja este uma imagem mental ou palpável, uma ação ou mera reação gestual, uma palavra ou um mero sentimento de alegria, de raiva... uma ideia, ou seja lá o que for- porque esse seja lá o que for que é criado na mente pelo signo, é outro signo (SANTAELLA, 2003, p.26)

No entanto, a profundidade e expansão de interpretar e compreender um fenômeno possui relação direta com as potencialidades e limitações de cada indivíduo ao utilizar a

\footnotetext{
${ }^{7}$ http://www.uab.furg.br/pluginfile.php/76597/mod_resource/content/2/texto_complementar_modelos_explicativ os_Ci\%C3\%AAncias.pdf

${ }^{8}$ http://www.uab.furg.br/pluginfile.php/76598/mod_resource/content/1/texto\%204_complementar_modelos_expl icativos_Ci\%C3\%AAncias.pdf
} 
complexa relação entre signos. Nesse aspecto, a semiótica nos permite analisar e descrever os produtos das linguagens presentes na natureza.

Pautando-se no fato de que todo o ser humano comunica seus pensamentos dentro de um contexto social utilizando a linguagem, caracterizada conforme mencionamos anteriormente, por agregar um conjunto de signos articulados permeado de significados que "[...] adquirem significação concreta no contexto da interlocução" (PINO, 2000, p.43), faz-se fundamental compreender que esta como forma de comunicação não se restringe apenas ao modo verbal (oral ou escrita), mas abarca também a forma não verbal, que igualmente reúne uma série de signos, que por si só comunicam e expressam significados aos sujeitos inseridos dentro do contexto social.

A partir do estudo de Sá (2018), podemos inferir que o sistema de signos característicos da linguagem abrange a língua específica de cada comunidade (materna) e constitui a especificidade de sua oralidade e escrita. Com isso, tomando o ser humano desde a sua infância, atribui-se às relações de conversação com outros indivíduos que constituem o âmbito de sua comunidade, como a propiciadora da construção do seu sistema linguístico. Ao iniciarem a fase escolar, as crianças são inseridas em uma comunidade cuja mediação é proposta em atividades e ações dos professores, para Wells (2001, p.49, tradução nossa) “[...] isto dá origem a uma nova etapa de sua aprendizagem que supõe novas maneiras de empregar a linguagem e novas maneiras de pensar".

O contato do ser humano com a ciência, e com os conceitos científicos, emprega definições e explicações, construídas com o apoio do professor, mas que não implicam numa relação de experiências diretas e pessoais como acontece com os conceitos cotidianos. Assim, estes são assistemáticos e são aprendidos a partir da emersão espontânea em decorrência das atividades cotidianas que o indivíduo desempenha; enquanto que o primeiro cujo contato inicial ocorre no contexto escolar, é aprendido como parte de um sistema de conceitos, que também influencia na reestruturação dos conceitos espontâneos (WELLS, 2001).

No âmbito da aprendizagem das Ciências Naturais, podemos afirmar que uma nova etapa surge e nela recorre-se a outras formas de se utilizar a linguagem e o pensamento. Essa linguagem surge como resultado de um fazer ciência e constitui-se de uma semântica própria, dotada de significados que podem ser expressos de muitas maneiras em diferentes contextos por meio de uma gramática e de um vocabulário constituído de distintos argumentos científicos, mantendo padrão o conteúdo científico.

É desta forma que a comunicação acontece dentro de uma comunidade, ou seja, sujeitos que compartilham dos mesmos interesses e convicções comunicam, nesse caso, sobre 
ciência através da representação simbólica de signos, como os modelos científicos, por exemplo. Tais discussões nos levam a pensar no porquê de alguns alunos não compreenderem conceitos da ciência e em consequência disso apresentarem um grande desinteresse para com a mesma.

Podemos atribuir à maneira com que a linguagem é utilizada para comunicar a ciência e significá-la aos alunos? Pertencendo os professores a uma comunidade de pessoas que utilizam a linguagem da ciência para dar significado a cada tema, estariam os alunos empregando de uma linguagem própria para essa compreensão? Deveriam os alunos estar imersos nessa comunidade em que pessoas comunicam sobre ciência para apropriarem-se da sua linguagem?

De acordo com Lemke (1997), o caminho para refletir sobre tais questionamentos está em introduzir os sujeitos em formação como membros ativos da comunidade científica. De maneira que, nesse contexto a apropriação da linguagem poderá ocorrer mediante escritas, leituras, argumentações, diálogos, análises, resoluções de problemas, mediados pelos que dominam esse "idioma", os professores, possibilitando que através das interações os a signifiquem nas mais diversas situações que os cercam.

Tendo em vista, a formação inicial de professores de Ciências na perspectiva interdisciplinar, foco deste trabalho, Justi (2015) aponta que é preciso promover um ensino que esteja motivado a produzir um conhecimento mais aproximado da própria ciência, ou seja, o mais autêntico possível. Para isso, requer se pensar em práticas que envolvam ativamente os estudantes a ponto de possibilitar a aprendizagem da ciência.

Valendo-se de que a ciência é resultado da construção humana, passível de erros e de verdades não únicas e absolutas; e que tem os seus estudos motivados pela curiosidade de entendimento de fenômenos e situações presentes no mundo; bem como tem por objetivo produzir conhecimento num processo dinâmico e não-linear. Ao alinharmos essas ideias com práticas epistêmicas ${ }^{9}$ para a aprendizagem da ciência, temos a modelagem como via de acesso para isso.

Pautados pelo fato de que modelos são produções da ciência, visando o entendimento e a visualização do mundo microscópico e abstrato, a fim de propiciar explicações, previsões e simulações, bem como à elaboração e expansão de teorias. A modelagem configura-se como produção de modelos, que também implica na sua validação e utilização. Ainda que não

\footnotetext{
${ }^{9}$ No sentido de gerar e consolidar conhecimentos científicos.
} 
exista um caminho único para o processo que envolve a modelagem, para Justi (2015) este deve constituir-se como dinâmico e criativo.

Dessa maneira, um ensino fundamentado na modelagem faz-se indissociado de habilidades argumentativas, isto é, em cada processo da produção de modelos os estudantes podem articular os seus conhecimentos, decidirem a forma com que poderão representá-los, testarem os modelos considerando dados empíricos ou teóricos e ainda avaliarem a aplicação dos mesmos, tudo isso, utilizando-se de uma linguagem científica para tecer os seus argumentos. Assumimos assim a linguagem científica como uma modalidade da linguagem semiótica, em que recorre-se a ela para o entendimento de fenômenos da natureza.

\section{Linguagens emergentes na construção dos modelos explicativos}

Utiliza-se como instrumento para a coleta de informações qualitativas, as linguagens construídas e registradas em uma das aulas presentes no ambiente virtual de aprendizagem AVA Moodle do curso. E para isso nosso enfoque qualitativo baseia-se na etnopesquisaformação, na qual o estudo dos fenômenos não ocorre isoladamente do seu contexto social e as investigações tecidas estão na imersão do pesquisador no campo de pesquisa em aproximação com o objeto de estudo (FERREIRA E BRITO, 2009).

Considerando que os modelos explicativos construídos e as interações entre os sujeitos ocorreram através da interface/ferramenta fórum, ressaltamos como critério para a seleção e inclusão nesta análise, o tópico aberto por cada aluno no fórum com maior interação entre os sujeitos de cada polo, com exceção apenas do polo de Novo Hamburgo, conforme nos mostra a figura 2, em que os estudantes não retornaram ao feedback dos tutores e não interagiram entre si. Assim, em Santo Antônio da Patrulha temos quatro interações, em São Lourenço do Sul oito interações e em Santa Vitória do Palmar nove interações. Para uma melhor visualização, disponibilizamos a seguir na tabela 1, algumas informações referentes aos tópicos abertos pelos alunos no fórum e que contêm o maior número de interações.

Tabela 1 - Interações que constituíram a produção dos modelos explicativos.

\begin{tabular}{|c|c|c|}
\hline Polo & Linguagens & Interações \\
\hline \hline Santo Antônio da \\
Patrulha & $\begin{array}{c}\text { Imagens, } \\
\text { textos, } \\
\text { esquemas }\end{array}$ & 4 \\
\hline São Lourenço do Sul & Textos e & 8 \\
\hline
\end{tabular}




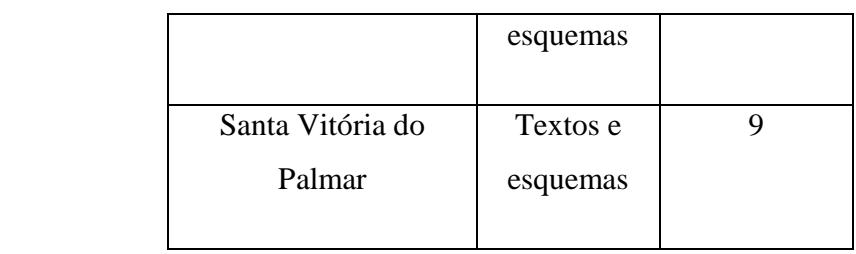

Fonte: AVA MOODLE DO CURSO DE LICENCIATURA EM CIÊNCIAS

No tópico de maior interação do polo de Santo Antônio da Patrulha, a modelagem com vistas a compreensão do fenômeno presente na situação audível e visível no vídeo disponibilizado pelos professores formadores, é representada inicialmente por uma das estudantes através de ilustrações e esquemas. Estas continham explicações que transitaram entre a composição da matéria, a natureza do som e a energia envolvida no processo. A mediação de uma das tutoras em meio a esta construção agregou diálogos e a proposição de questionamentos, como por exemplo: "Considerando que você destaca a presença de diferentes sons produzidos. Como a onda sonora chega até os nossos ouvidos? Que fatores podem influenciar nessas diferenças sonoras?”. Registramos neste momento o convite para que a estudante retomasse o que já havia desenvolvido, a fim de aprimorar sua construção, um movimento colaborativo para alçar modelos explicativos mais completos.

No tópico aberto pelo estudante do polo de São Lourenço do Sul, além da interação com uma das tutoras, houve também a colaboração de quatro estudantes, uma delas coloca: "[...] as pedras por estarem se movendo produzem energia". Observamos no decorrer desse processo investigativo que as ideias prévias dos estudantes foram levadas em consideração e aprimoradas na medida em que se buscava a aproximação e embasamento coerente com os saberes científicos para a compreensão do fenômeno.

Esse envolvimento ativo dos estudantes, além de possibilitar um olhar mais crítico sobre a ciência, os coloca em uma posição de reflexão sobre o fato de que o conhecimento científico é uma produção humana e que não se limita apenas aos cientistas. Em Paganini, Justi e Mozzer (2014, p.1020, grifo dos autores) assumimos que estas interações colaborativas entre professores/tutores e alunos podem ser definidas como “[...] processos de coconstrução de conhecimento", que conferem à mediação exercida formas e ações que visam fomentar um ensino mais significativo.

De acordo com Pino (2000, p.38, grifos do autor) os processos de coconstrução do conhecimento requerem a presença da mediação que se configura como "[...] toda a intervenção de um terceiro "elemento" que possibilite a interação entre os "termos" de uma relação". Assim a mediação pode constituir o argumentar, o refutar, o avaliar e repensar os saberes prévios dos alunos, bem como, a relação de interação entre professor/tutor e 
estudantes. O processo de mediação da construção do conhecimento acontece com auxílio do professor/tutor que levanta indagações, desencadeia discussões entre os próprios estudantes convidando-os a dialogar, direciona as produções dos alunos em proximidade com os conteúdos científicos, propõe materiais de apoio, ou seja, corrobora para que os próprios modelos explicativos construídos em meio a interação constituam mediadores da aprendizagem. É nesse âmbito que Pino (2000, p.39) denomina a mediação semiótica como sendo "[...] a mediação dos sistemas de signos [...]", que permeados pela linguagem expressam significados e influenciam nas ações semióticas dentro do contexto de atuação.

No tópico do último polo em questão, Santa Vitória do Palmar, a interação entre os estudantes foi mais expressiva se comparada com os polos anteriores, afirmando a ideia trazida por Paganini, Justi e Mozzer (2014) de que “[...] os estudantes também podem desempenhar um importante papel mediador durante o processo de coconstrução. Entretanto, os questionamentos utilizados pelos estudantes são diferentes dos questionamentos utilizados pelo professor”. Diante disso, apesar de indagações como: “[...] o que faz você pensar que o material das caixas é de papelão?”, não carregarem uma intencionalidade pedagógica, constituem momentos em que os estudantes de forma livre podem expor suas ideias, observações e hipóteses, sem que o professor tenha tecido qualquer tipo de contribuição à priori.

\section{Considerações finais}

Após as discussões tecidas no decorrer deste trabalho, evidenciamos que a semiótica compreende muitos tipos de linguagens, dentre elas a científica, e está implicada na comunicação social exercida por intermédio dos signos que constituem as mediações nos processos investigativos dos modelos explicativos. Na análise observamos que esse processo investigativo é ampliado pelo diálogo fortemente pautado em questionamentos entre os professores/tutores a partir da interação com a linguagem do vídeo. Neste âmbito de coconstrução do conhecimento pela modelagem por sujeitos imersos ativamente na comunidade de formação de professores de Ciências interdisciplinar, podemos reforçar as discussões tecidas anteriormente de que existe uma linguagem científica específica neste meio, que sob uma perspectiva interdisciplinar agrega os saberes das áreas que compõem as Ciências Naturais.

Ainda que os modelos científicos fruto de uma construção histórica, sejam provisórios e inacabados, auxiliam na compreensão do que pode estar ocorrendo microscopicamente em um fenômeno da natureza e ainda a tecer explicações sobre um mesmo fenômeno a partir de 
muitas interpretações. Ao permitir que os estudantes construam seus próprios modelos explicativos, possibilita-se a interação tanto com a linguagem dos materiais de estudo disponíveis na sala de aula virtual (textos e vídeo) quanto pela linguagem entre os professores/tutores e estudantes, na expressão dos significados e na composição das ações e práticas semióticas nesta comunidade. Assume-se assim a linguagem científica como uma modalidade da linguagem semiótica, em que se recorre a ela para o entendimento de fenômenos da natureza.

\section{Referências}

BRASIL. Ministério da Educação, Conselho Nacional de Educação, Câmara de Educação Básica. Escassez de professores no Ensino Médio: Propostas estruturais e emergenciais. Brasília, 2007.

FERREIRA, M.C.A.; BRITO, T.T.R. O itinerário investigativo: a etnopesquisa crítica/formação. Revista Práxis Educacional, v.11, n.20, p.311-332, set./dez.2015. ISSN $2178-2679$. Disponível em: http://periodicos.uesb.br/index.php/praxis/article/viewFile/5286/5067. Acesso em: 20 mai.2018

JUSTI, Rosária. Relações entre argumentação e modelagem no contexto da ciência e do ensino de ciências. Revista Ensaio. Belo Horizonte, MG, v.17, p.31-48, nov.2015. ISSN 1983- 2117. Disponível em: http://www.scielo.br/scielo.php?script=sci_arttext\&pid=S198321172015000400031\&lng=pt\&tlng=pt. Acesso em: 20 mai.2018.

LEMKE, J. Aprender a hablar ciência: lenguaje, aprendizaje y valores. Barcelona: Editorial Paidós, 1997. 272 p.

PAGANINI, P.; JUSTI, R.; MOZZER, N. B. Mediadores na coconstrução do conhecimento de ciências em atividades de modelagem. Revista Ciência e Educação, Bauru, v. 20, n. 4, p. 1019-1036, 2014. ISSN - 1980- 850X. Disponível em: http://www.scielo.br/scielo.php?script=sci_arttext\&pid=S151673132014000400016\&lng=pt\&tlng=pt. Acesso em: 19 dez.2018.

PINO, A. P. O conceito de mediação semiótica em Vygotsky e seu papel na explicação do psiquismo humano. Caderno CEDES, Campinas, Papirus, n. 24 (2000) 38 - 51.

SÁ, Ana Paula Suitsu de. Linguagem científica: características e importância. Revista Âmbito Jurídico, XX, n.166, p.01-05, nov. 2017. ISSN - 1518-0360. Disponível em: http://www.ambitojuridico.com.br/site/?n_link=revista_artigos_leitura\&artigo_id=19776\&r evista caderno=27. Acesso em: 29 out.2018.

SANTAELLA, L. O que é Semiótica? São Paulo: Brasiliense, 2003. 87 p. 
UNIVERSIDADE FEDERAL DO RIO GRANDE. Curso de Licenciatura em Ciências-Rio Grande/RS. In: Projeto Pedagógico do Curso de Graduação a distância Licenciatura em Ciências/FURG, 2018.

WELLS, G. Indagación Dialógica: hacia una teoría y una práctica socioculturales de la educación. Buenos Aires: Editorial Paidós, 2001. 374 p. 